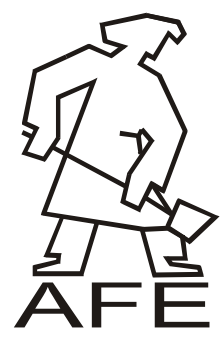

\title{
Model of Cu-Al-Fe-Ni Bronze Crystallization
}

\author{
B.P. Pisarek \\ Department of Materials Engineering and Production Systems, Lodz University of Technology \\ 1/15 Stefanowskiego Street 90-924 Lodz, Poland \\ Corresponding author. E-mail address: boguslaw.pisarek@p.lodz.pl
}

Received 29.05.2013; accepted in revised form 04.06.2013

\begin{abstract}
According to the analysis of the current state of the knowledge shows that there is little information on the process of phase transformations that occur during the cooling $\mathrm{Cu}-\mathrm{Al}-\mathrm{Fe}-\mathrm{Ni}$ hypo-eutectoid bronzes with additions of $\mathrm{Cr}$, Mo and/or $\mathrm{W}$, made additions individually or together, for the determination of: the type of crystallizing phases, crystallizing phases, order and place of their nucleation.

On the basis of recorded using thermal and derivative analysis of thermal effects phases crystallization or their systems, analysis of the microstructure formed during crystallization - observed on the metallographic specimen casting ATD10-PŁ probe, analysis of the existing phase equilibrium diagrams forming elements tested $\mathrm{Cu}-\mathrm{Al}-\mathrm{Fe}-\mathrm{Ni}$ bronze, with additions of $\mathrm{Cr}$, Mo, $\mathrm{W}$ and/or Si developed an original model of crystallization and phase transformation in the solid state, the casting of high quality Cu-Al-Fe-Ni bronze comprising: crystallizing type phase, crystallizing phase sequence, place of nucleation.
\end{abstract}

Keywords: Theoretical basis of foundry processes, Thermal and derivative analysis, Microstructure, Cu-Al-Fe-Ni bronze, Model of crystallization

\section{Introduction}

Figure 1 presents the superposition of phase equilibrium diagrams of the $\mathrm{Cu}-\mathrm{Al}-5 \% \mathrm{Fe}-5 \% \mathrm{Ni}[1,2]$. According to Brezina [1], eutectoid phase transformation $\beta \rightarrow \alpha+\gamma_{2}$ occurs at a constant temperature, and Cook et al [2] claim that this transition occurs at a temperature of TEs $\div$ TEf (TEs-eutectoid transformation start temperature, TEf-temperature end eutectoid). The charts of these

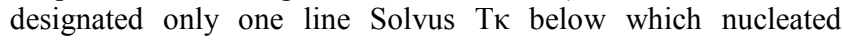
and grows in bronze $\kappa$ phase.

Concentration $\mathrm{C} 1$ marked on the chart alloy crystallizes without eutectoid transformation, and the concentration of C2 hypoeutectoid alloy. According to [1] (Fig. 1), the process of creating a microstructure of aluminum bronze with a concentration of $\mathrm{C} 1$ takes place in three stages:

- $\beta$-phase crystallization directly from the liquid $\mathrm{L}(\mathrm{L} \rightarrow \beta)$,

- transformation part of the $\beta$ phase in the phase $\alpha(\beta \rightarrow \alpha)$,

- $\quad \kappa$ phase separation from $\beta$ phase $(\beta \rightarrow \beta+\kappa)$ and/or $\alpha$ $(\alpha \rightarrow \alpha+\kappa)$.
The process of formation of the microstructure of Al-bronze with a concentration of $\mathrm{C} 2$ takes place in four steps:

- $\quad \beta$-phase crystallization directly from the liquid $(\mathrm{L} \rightarrow \beta)$,

- $\quad \kappa$ phase separation from $\beta$ phase $(\beta \rightarrow \beta+\kappa)$,

- $\quad$ transformation part of the $\beta$ phase in the phase $\alpha(\beta \rightarrow \alpha)$,

- $\quad$ transformation of the remaining $\beta$ phase in the eutectoid $\alpha+\gamma_{2}\left(\beta \rightarrow \alpha+\gamma_{2}\right)$.

Further research Al-Cu-Fe-Ni bronzes revealed that the microstructure of these bronzes are identified morphologically different phases of $\kappa$ [3 to 5]. For the bronze with a concentration of $\mathrm{Al}$ in the range described in the chart by Brezina points $\mathrm{A} \div \mathrm{B}$ (Fig. 1), set the temperature of phase transitions [6]. K-phases are divided into four main types: $\kappa_{\mathrm{I}}, \kappa_{\mathrm{II}}, \kappa_{\mathrm{III}}$ and $\kappa_{\mathrm{IV}}[3 \div 6]$. On the basis of DTA research and metallographic Brezina [3] presented a schematic form of $\kappa$-phase precipitates in alloys $\mathrm{CuAl10Fe} 5 \mathrm{Ni} 5$ cooling down with speed of about $0.5^{\circ} \mathrm{C} / \mathrm{min}$. Brezina did not explain clearly the stage of formation of $\kappa_{\mathrm{I}}$-phases. Its location in a typical intergrain area, on the $\beta$-phase, suggesting the possibility of crystallization of these phases of the last portion of the liquid bronze particularly enriched in admixtures of iron. 


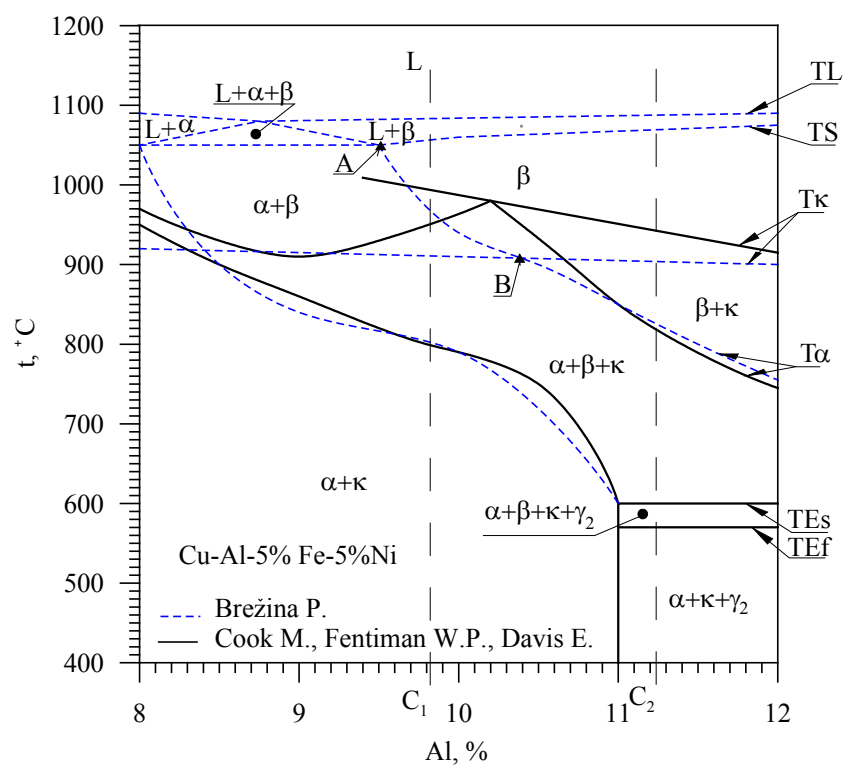

Fig. 1. Superposition of phase equilibrium diagrams $\mathrm{Cu}-\mathrm{Al}-5 \% \mathrm{Fe}-5 \% \mathrm{Ni}[1,2]$

A slightly different version of the $\kappa$-phase position presented Jahanafrooz et al $[4,5]$ locating $\kappa_{\mathrm{I}}$ phase within the phase $\alpha$.

The Department of Materials Engineering and Production Systems conducts research using thermal and derivative analysis (TDA) of ferro-alloys [8,9], aluminum [10,11] and copper, and especially $\mathrm{Cu}-\mathrm{Al}-\mathrm{Fe}-\mathrm{Ni}$ hypo-eutectoid bronze with additions of $\mathrm{Cr}$, Mo, $\mathrm{W}$ and/or $\mathrm{C}$ and $\mathrm{Si}[12 \div 15]$. Only the TDA method it is possible to keep track of thermal processes of crystallization of metals and their alloys. Using the TDA method are developed computer systems of quality control liquid alloys [16].

After analyzing the current state of knowledge suggests that there is no systematic information on the process of phase transformations that occur during cooling $\mathrm{Cu}-\mathrm{Al}-\mathrm{Fe}-\mathrm{Ni}$ hypo-eutectoid bronze with additions of $\mathrm{Cr}$, Mo and/or W, made additions individually or jointly, in terms of the definition: the type of crystallizing phases, the order crystallizing phases and place of their nucleation.

\section{Work methodology}

Table 1 presents the range of the chemical composition of the test bronze.

Table 1.

Chemical composition of the test bronze

\begin{tabular}{|c|c|c|c|c|c|c|c|c|c|}
\hline & \multicolumn{9}{|c|}{ Chemical composition, \% } \\
\hline & $\mathrm{Al}$ & $\mathrm{Fe}$ & $\mathrm{Ni}$ & $\mathrm{Mn}$ & $\mathrm{Si}$ & $\mathrm{Cr}$ & Mo & $\mathrm{W}$ & $\mathrm{Cu}$ \\
\hline min. & 10.38 & 4.43 & 4.50 & 0.3 & 0.02 & 0.01 & 0.00 & 0.00 & 8 \\
\hline $\max$. & 10.89 & 4.92 & 5.54 & 0.8 & 0.14 & 0.42 & 0.41 & 0.04 & \\
\hline
\end{tabular}

The evaluation method of thermal and derivative analysis (TDA) cooling $(\mathrm{t}=\mathrm{f}(\tau))$, kinetics $\left(\mathrm{dt} / \mathrm{d} \tau=\mathrm{f}^{\prime}(\tau)\right)$ and dynamics $\left(\mathrm{d}^{2} \mathrm{t} / \mathrm{d} \tau^{2}=\mathrm{f} "(\tau)\right)$ crystallization and phase transformation in solid state of $\mathrm{Cu}-\mathrm{Al}-\mathrm{Fe}-\mathrm{Ni}-(\mathrm{Cr}, \mathrm{Mo}, \mathrm{W}, \mathrm{CrMoW})$ bronze was carried out using the apparatus CRYSTALDIGRAPH. Supported of a computer software for thermal and derivative analysis of alloys were determined characteristic points on the derivative curve of each sample bronze. Sample TDA curves of $\mathrm{CuAl11Fe} 5 \mathrm{Ni} 6$ bronze shown in Figure 2. They show that the derivative curve thermal effects are the following:

$\mathrm{Y}-\mathrm{C}-\mathrm{H} \quad$ - primary crystallization $\beta$ phase

$$
(\mathrm{L} \rightarrow \beta),
$$

P-Q-R - crystallization $\kappa_{\text {II }}$ phase

$$
\left(\beta \rightarrow \beta+\kappa_{\mathrm{II}}\right),
$$

J-K-L - partial transformation of $\beta$ phase in the phase $\alpha$ $(\beta \rightarrow \beta+\alpha)$,

L-T-U - separation in the $\alpha$ phase, supersaturated $\mathrm{Ni}$,

$$
\kappa_{\text {III }} \text { phase } \quad\left(\alpha_{(\mathrm{Ni})} \rightarrow \alpha+\kappa_{\mathrm{III}}\right),
$$

$\mathrm{U}-\mathrm{V}-\mathrm{W}$ - separation in the $\alpha$ phase, supersaturated Fe, $\kappa_{\text {IV }}$ phase $\quad\left(\alpha_{(\mathrm{Fe})} \rightarrow \alpha+\kappa_{\mathrm{IV}}\right)$,

$\mathrm{M}-\mathrm{N}-\mathrm{O}$ - eutectoid transformation of the remaining $\beta$ phase saturated with $\mathrm{Al}$, in the eutectoid $\quad\left(\beta \rightarrow \alpha+\gamma_{2}\right)$.

To describe the characteristic of thermal processes occurring during the primary and secondary crystallization (phase transformation in solid state) uses the following values:

- temperature of the bronze during registration characteristic points $\mathrm{t},{ }^{\circ} \mathrm{C}$,

- the first derivative of the temperature with respect to time for these points $\mathrm{dt} / \mathrm{d} \tau,{ }^{\circ} \mathrm{C} / \mathrm{s}$,

- the tangent of the angle of slope on the interpolated distance between characteristic points $\operatorname{tg}(\alpha) \approx \mathrm{d}^{2} \mathrm{t} / \mathrm{d} \tau^{2},{ }^{\circ} \mathrm{C} / \mathrm{s}^{2}$,

- the time from the beginning of the measurement of characteristic points on the derivative curve (crystallization curve) $\tau, \mathrm{s}$.

In order to visualize the different phases in the microstructure metallographic specimens were etched with $\mathrm{Mi} 20 \mathrm{Cu}$ reagent. The microstructure of the test specimens bronze were observed optical microscope Nikon Eclipse MA200.

To identify the chemical composition at different points of the sample cast microstructure was observed by scanning electron microscopy Hitachi scanning electron microscope S-4200 at an accelerating voltage of $25 \mathrm{keV}$, equipped with EDS analyzer.

\section{Description of achieved results of own researches}

\subsection{Crystallization of the complex aluminum bronze}

Figure 2 presents the TDA characteristics hypo-eutectoid bronze, representative of the amount made additions on the alloying elements (Table 1). Made additions alloying elements $(\mathrm{Cr}, \mathrm{Mo}$ and/or W) dissolve in varying degrees in specific phases of the test bronze without affecting the change in the type of crystalliz- 
ing phases and, consequently, the amount of the thermal effects of crystallization, recorded on the characteristics of TDA. Made additions alloy additives influence: the temperature $t$, the kinetics of $\mathrm{dt} / \mathrm{d} \tau=\mathrm{f}^{\prime}(\tau)$ and the dynamics of $\mathrm{Z} \approx \mathrm{d}^{2} \mathrm{t} / \mathrm{d} \tau^{2}$ thermal crystallization processes forming phase microstructure of bronze and time $\tau$ start and duration of each phase transformations occurring during primary crystallization and secondary of bronze.

The real temperature of crystallization of different phases or their system is as follows:

\begin{tabular}{|c|c|c|c|}
\hline liquidus $(\mathrm{L} \rightarrow \beta)$ & $\mathrm{tC}$ & $=$ & 1082.6 \\
\hline solidus $(\beta)$ & tH & $=$ & 1023.3 \\
\hline$\kappa_{\text {II }}$ phase crystallization & tQ & $=$ & 897.4 \\
\hline$\alpha$ phase crystallization $\left(\alpha_{(\mathrm{Ni})}, \alpha_{(\mathrm{Fe})}\right)$ & tK & $=$ & 812.2 \\
\hline $\begin{array}{l}\kappa_{\mathrm{III}} \text { phase crystallization } \\
\alpha_{(\mathrm{Ni})} \rightarrow \alpha+\kappa_{\mathrm{III}}\end{array}$ & $\mathrm{tT}$ & $=$ & 736.6 \\
\hline $\begin{array}{l}\kappa_{\mathrm{IV}} \text { phase crystallization } \\
\alpha_{(\mathrm{Fe})} \rightarrow \alpha+\kappa_{\mathrm{IV}}\end{array}$ & $\mathrm{tV}$ & $=$ & 702.7 \\
\hline
\end{tabular}

$\mathrm{CuAl11Fe} 5 \mathrm{Ni} 6$ bronze microstructure in the as-cast, observed metallurgical microscope is shown in Figure $3(\mathrm{a}, \mathrm{b})$. It shall be composed of the phases: $\kappa_{\text {II }}, \alpha+\kappa_{\text {III }}, \alpha+\kappa_{\text {IV }}, \alpha+\gamma_{2}$. Figure 4 shows the microstructure of the test bronze observed the electron microscope. Results of chemical analysis points of the selected area, are presented in Figure 5. In the bronze $\mathrm{CuAl} 11 \mathrm{Fe} 5 \mathrm{Ni} 6$ microstruc- ture in the as-cast, the chemical composition has been identified in the following types of phases or phase systems: $\kappa_{\mathrm{II}}, \alpha+\kappa_{\mathrm{III}}, \alpha+\gamma_{2}$. In the $\kappa_{\text {II }}$ phase of the mass concentrations of individual elements have changed as follows: Fe $29.43 \div 66.55 \%$, Si $3.93 \div 8.57 \%$, Al $3.97 \div 6.87 \%$, Ni $2.95 \div 4.08 \%$, Mn $0.84 \div 1.72 \%$, Cu $16.23 \div 54.84 \%$. In the presented studies show that the $\kappa_{\text {II }}$ phase during crystallization highly saturated elements, respectively: $\mathrm{Fe}, \mathrm{Si}, \mathrm{Mn}$, and to a lesser extent, $\mathrm{Al}$ and $\mathrm{Ni}$, as compared to the concentration of these elements in the alloy (Table 1).

The phases system $\alpha+\kappa_{\text {III }}$ mass concentrations of individual elements have changed as follows: Al about 9.85\%, Ni 5.64 $\div 5.92 \%$, Fe $1.52 \div 1.59 \%$, Mn $0.12 \div 0.33 \%$, Si $0.14 \div 0.19 \%, \quad \mathrm{Cu}$ $82.20 \div 82.66 \%$. $\mathrm{K}_{\mathrm{III}}$ phase (Ni-rich) during the crystallization phase system $\left(\alpha+\kappa_{\text {III }}\right)$ strongly saturated elements, respectively: $\mathrm{Ni}$ and $\mathrm{Mn}$, and, to a lesser extent, $\mathrm{Fe}$ and $\mathrm{Si}$, compared to the concentration in the alloy (see Table 1). Characteristic of the system for the crystallization phase is the persistence $\mathrm{Al}$ concentration constant level of the order of $9.85 \%$.

In phases system $\left(\alpha+\gamma_{2}\right)$, the mass concentrations of the individual elements are approximately: $11.58 \% \mathrm{Al}, 6.26 \% \mathrm{Ni}, 1.53 \% \mathrm{Fe}$, $0.23 \% \mathrm{Si}, 0.18 \% \mathrm{Mn}, 80.21 \% \mathrm{Cu}$.

The characteristic of this system for the phase crystallization is the increased concentration of $\mathrm{Al}$ (as compared to the concentration of $\mathrm{Al}$ in the phase $\kappa_{\text {II }}$ or phase system $\alpha+\kappa_{\text {III }}$ ) of about $11.58 \%$ - in conditions of equilibrium in the system $\mathrm{Cu}-\mathrm{Al}$ eutectoid point is designated for the concentration of $\mathrm{Al}=11.8 \%$.

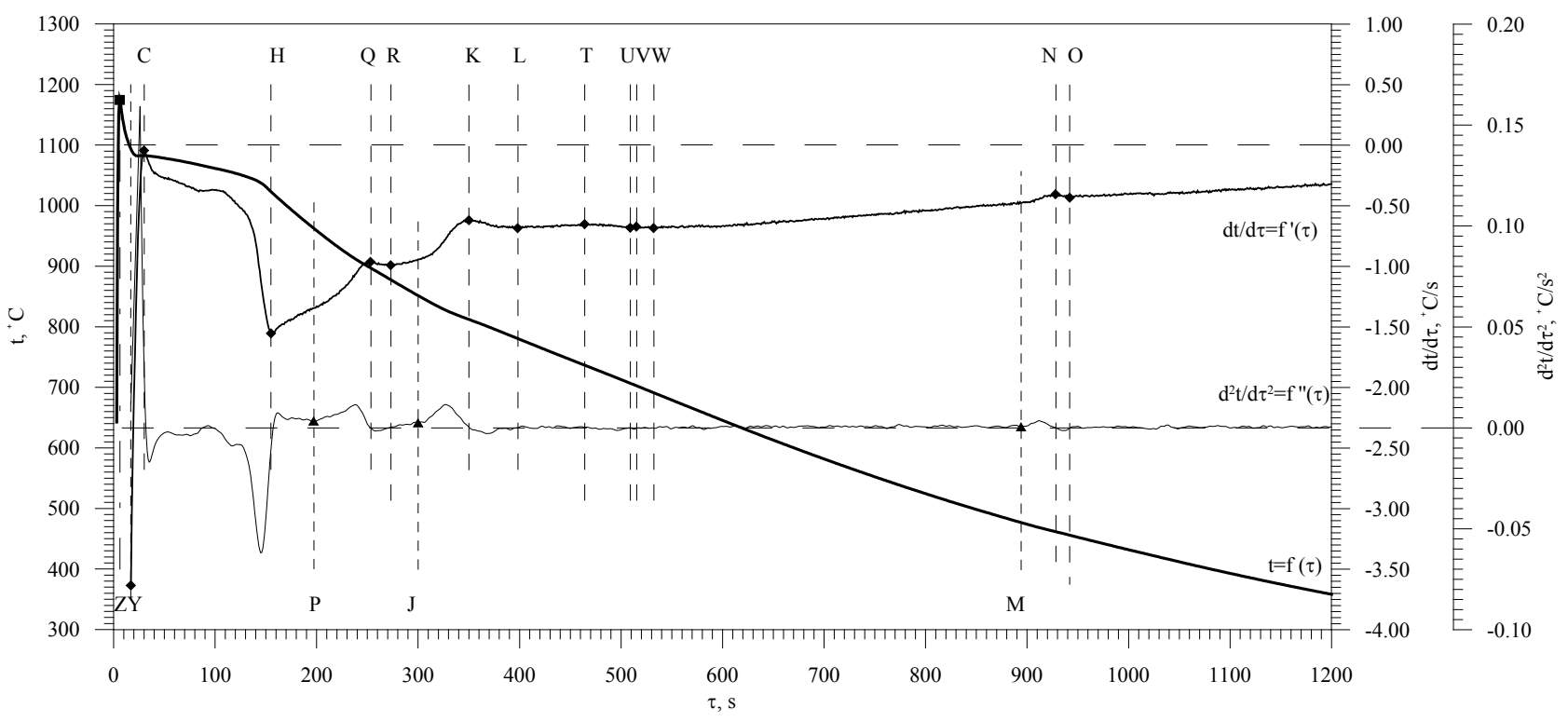

\begin{tabular}{|c|c|c|c|c|c|c|c|c|c|c|c|c|c|c|c|c|c|}
\hline Point & Z & Y & $\mathrm{C}$ & $\mathrm{H}$ & $\mathrm{P}$ & Q & $\mathrm{R}$ & $\mathrm{J}$ & K & $\mathrm{L}$ & $\mathrm{T}$ & $\mathrm{U}$ & V & W & M & $\mathrm{N}$ & $\mathrm{O}$ \\
\hline$\tau, \mathrm{s}$ & 6 & 17 & 30 & 155 & 197 & 253 & 273 & 300 & 350 & 398 & 464 & 509 & 515 & 532 & 894 & 928 & 942 \\
\hline $\mathrm{t},{ }^{\circ} \mathrm{C}$ & 1174.7 & 1093.5 & 1082.6 & 1023.3 & 962.9 & 897.4 & 877.7 & 851.5 & 812.2 & 780.7 & 736.6 & 706.8 & 702.7 & 691.2 & 476.9 & 461.7 & 455.9 \\
\hline $\mathrm{dt} / \mathrm{d} \tau,{ }^{\circ} \mathrm{C} / \mathrm{s}$ & 75.84 & -3.63 & -0.04 & -1.55 & -1.34 & -0.96 & -0.99 & -0.94 & -0.62 & -0.68 & -0.65 & -0.68 & -0.67 & -0.68 & -0.48 & -0.40 & -0.43 \\
\hline $\mathrm{Z}^{*} 10^{-3},{ }^{\circ} \mathrm{C} / \mathrm{s}^{2}$ & - & 732.49 & -2.39 & -63.48 & 10.40 & - & -1.10 & 10.97 & - & -1.08 & 0.35 & -0.71 & 0.46 & -0.44 & 3.11 & - & -1.27 \\
\hline
\end{tabular}

Fig. 2. TDA characteristics: $\mathrm{t}=\mathrm{f}(\tau), \mathrm{dt} / \mathrm{d} \tau=\mathrm{f}^{\prime}(\tau), \mathrm{Z} \approx \mathrm{d}^{2} \mathrm{t} / \mathrm{d} \tau^{2}=\mathrm{f}$ “ ( $(\tau)$; CuAl11Fe5Ni6 bronze 


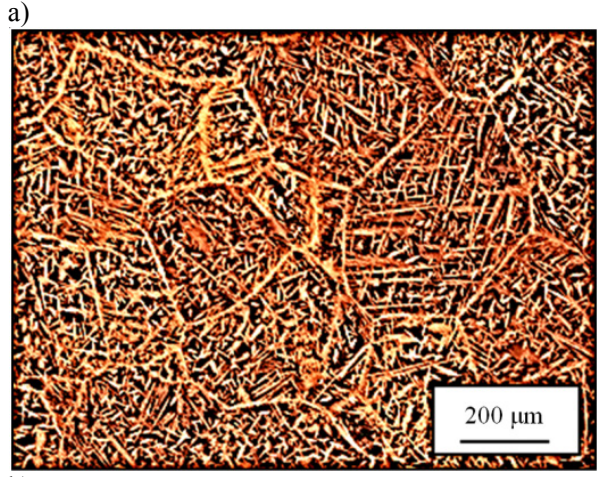

b)

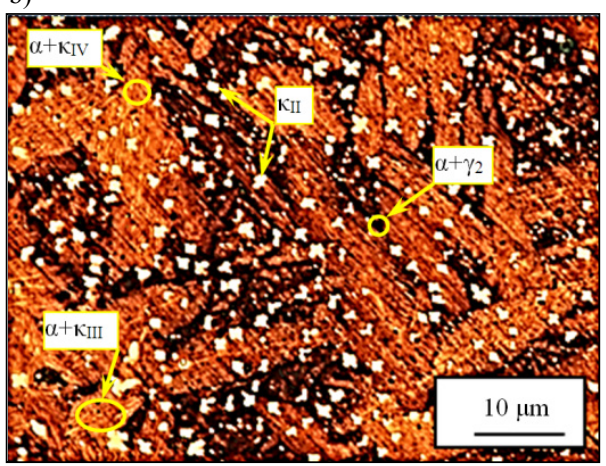

Fig. 3. Microstructure of CuAl11Fe5Ni6 bronze $(a, b)$

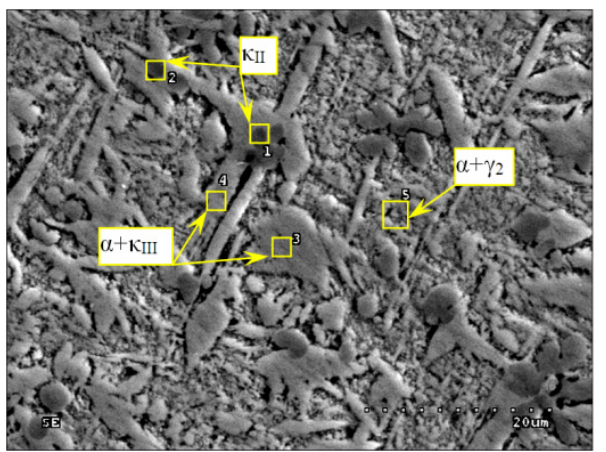

Fig. 4. Microstructure of CuAl11Fe5Ni6 bronze with marked points of analysis from Scanning Electron Microscope

Point 1

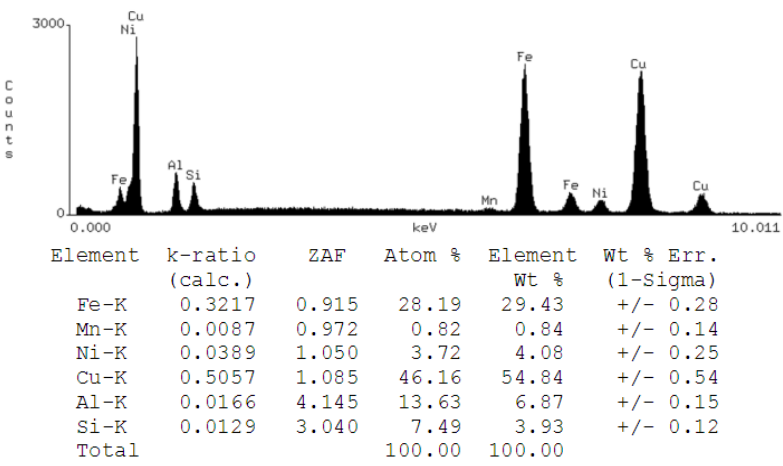

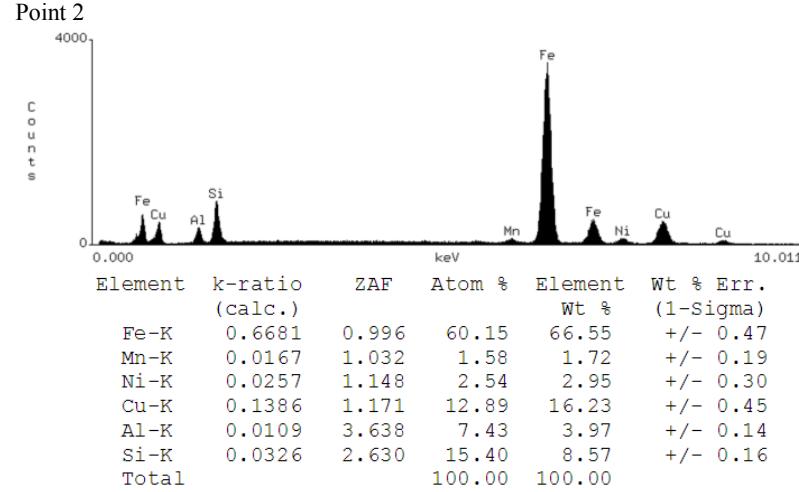

Point 3

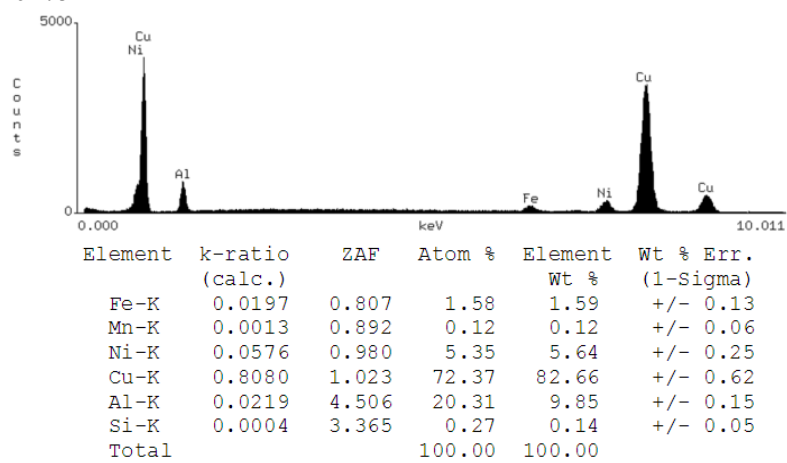

Point 4

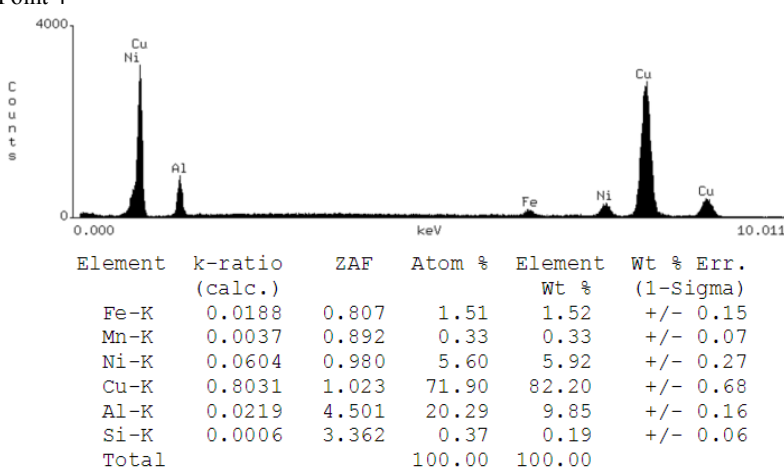

Point 5

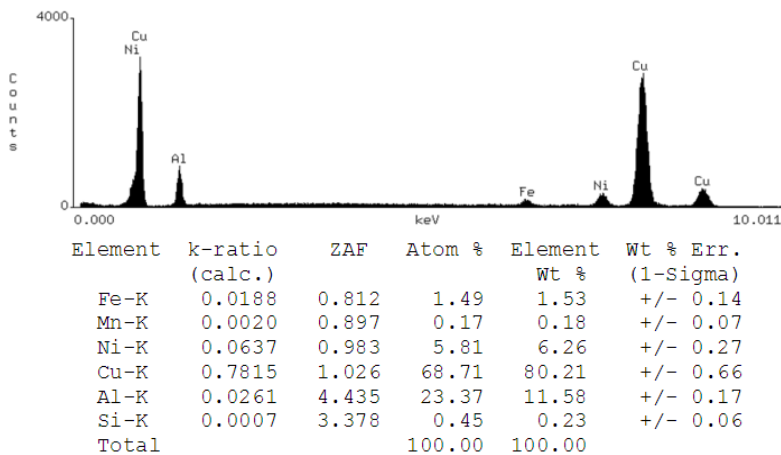

Fig. 5. Charts analysis and the results of the chemical composition at points 1 to 5 microstructure of $\mathrm{CuA} 111 \mathrm{Fe} 5 \mathrm{Ni} 6$ bronze, solidifying in the ATD10-PŁ sampler 


\subsection{Model of aluminum bronze crystallization}

A graphic model of crystallization and phase transformation in solid $\mathrm{Cu}-\mathrm{Al}-\mathrm{Fe}-\mathrm{Ni}$ bronzes hypo-eutectoid no intermetallic phases MM_X type (where $\mathrm{X}=\{\mathrm{Mo}, \mathrm{W}, \mathrm{Cr}, \mathrm{MoWCr}\}$ ) and $\kappa_{\mathrm{I}}$ is shown in Figure 6. This process is divided into stages I to VIII, in relation to the characteristic points that define the temperature of phase transformation in bronze, appointed by TDA method. After pouring bronze into the mould, the molten alloy is cools and transfer to its superheat (Stage I). After the alloy supercooling below the equilibrium liquidus temperature TL (Stage II), in liquid form on the walls of the mold and on the precipitate particles (the undissolved solid phase) contained in the bronze, nucleates $\beta$ phase and grows, up to the solidus temperature TS.

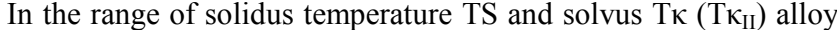
cools a single-phase (Stage III), with a non-equilibrium concentration of admixtures in grains of $\beta$ phase. After supercooling

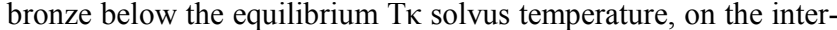
phase boundaries and within the $\beta$ phase, in areas rich in $\mathrm{Fe}$, nucleates and grows in the form of "rosettes", to the T $\alpha$ solvus temperature, intermetallic $\kappa_{\mathrm{II}}$ phase rich in iron and aluminum and high-melting alloy additions ( $\mathrm{Cr}, \mathrm{Mo}, \mathrm{W}, \mathrm{Si}$ ) (Stage IV). After supercooling bronze below the equilibrium solvus T $\alpha$ temperature, as a result of the increase in the solubility $\mathrm{Al}$ in the phase $\beta, \mathrm{Al}$ is diffusing from the phase boundary inwards grains of the phase $\beta$, and dealuminize the layer of the $\beta$ phase is changing into the phase $\alpha$, forming the outline of the primary $\beta$ phase (V s Stage, s-start, beginning of the $\beta \rightarrow \beta+\alpha$ transformation). Next, this process cover the inside of the $\beta$ phase. Nucleation and growth in the form of plates or "narrow lens", richer in alloying additives $\alpha$ phase, started in various places on the previously crystallized the $\alpha$ phase on interphase boundaries. Phase $\alpha$ may also nucleate close to $\kappa_{\mathrm{II}}$ phase precipitates, that during the nucleation and growth parent $\beta$ phase impoverished its not only high melting bronze admixtures, but also of aluminum. Hence also, impoverished into admixtures alloy and aluminium phase $\beta$, transforms, along with a fall in temperature, into the phase $\alpha$, with nonequilibrium concentration of admixtures. The excess aluminum in the increasing $\alpha$ phase, is relegated to $\beta$ phase, by diffusion, to the front of its crystallization. Al-rich phase $\beta$ is trapped in a small area between the plates and lens $\alpha$ phase (Stage V_f, f-finish, the end of the transformation $\beta \rightarrow \beta+\alpha)$. After supercooling bronze, below the equilibrium T $\kappa_{\text {III }}$ solvus temperature inside platelets or lenticular $\alpha$ phase precipitates, saturated nickel $(\alpha(\mathrm{Ni}))$, nucleate and grows $\kappa_{\mathrm{III}}$ intermetallic phase, rich in $\mathrm{Ni}$ and high-melting alloying elements $(\mathrm{Cr}, \mathrm{Mo}, \mathrm{W}, \mathrm{Si})$. Nucleation and growth phases $\kappa_{\text {III }}$ characterized by a certain analogy to the process of formation of pearlite in iron alloys. Nonequilibrium phase transformation of $\alpha$ phase, saturated $\mathrm{Ni}$ and alloying elements in the system of phases $\alpha+\kappa_{\text {III }}$, starts from the nucleation $\kappa_{\text {III }}$ phase in a plates. Growing the plate $\kappa_{\text {III }}$ phase, impoverishes $\alpha$ phase in admixtures, hence next lamellar $\kappa_{\mathrm{III}}$ phase separation are separated lanes $\alpha$ phase poor in alloy additives (Stage VI). In the $\alpha$ phase, poorer in $\mathrm{Ni}$ and the alloying elements, but richer in $\mathrm{Fe}(\alpha(\mathrm{Fe}))$, after the supercooling below the equilibrium $T \kappa_{\mathrm{IV}}$ solvus temperature, due to the decreasing solubility of $\mathrm{Fe}$ and of the alloying admixtures in this phase, nucleates and grows in the form of spheroidal precipitates intermetallic $\kappa_{\mathrm{IV}}$ phase, rich in Fe and alloying elements (Stage VII). The form of $\kappa_{\mathrm{IV}}$ phase precipitates is probably due to the fact, that precipitates of this phase takes place already at relatively low temperatures and diffusion of admixtures in the $\alpha$ phase may occur at a relatively short distance. After supercooling bronze below the TE equilibrium eutectoid temperature, the rest of the phase $\beta$ ( $\beta(\mathrm{Al})$ ), which has not been changed to $\alpha$ phase due to the high content of $\mathrm{Al}$, transforms into the eutectoid $\alpha+\gamma_{2}$ (Stage VIII).

As a result of the primary and secondary crystallization (phase transformation in solid state) in the microstructure bronze formed phase microstructure consisting of: $\kappa_{\mathrm{II}}+\left(\alpha+\kappa_{\mathrm{III}}\right)+\left(\alpha+\kappa_{\mathrm{IV}}\right)+\left(\alpha+\gamma_{2}\right)$.

Phase transformation and the transformation temperature range during cooling in the ATD10-PŁ sampler bronzes $\mathrm{Cu}-\mathrm{Al}-$ Fe-Ni with limited additions of $\mathrm{Cr}$, Mo, W and/or Si (Table 1) shown in Figure 7. Due to the fact that the cooling process of bronze in the sampler ATD10-PE occurs at a faster rate than in the conditions of equilibrium (which generates bigger supercooling in crystallization process) must be assumed, that the equilibrium crystallization temperature and phase transformation in the solid state are relatively slightly higher than the set ATD method in the sampler.

temperature cooling of the ATD10-PLsampler

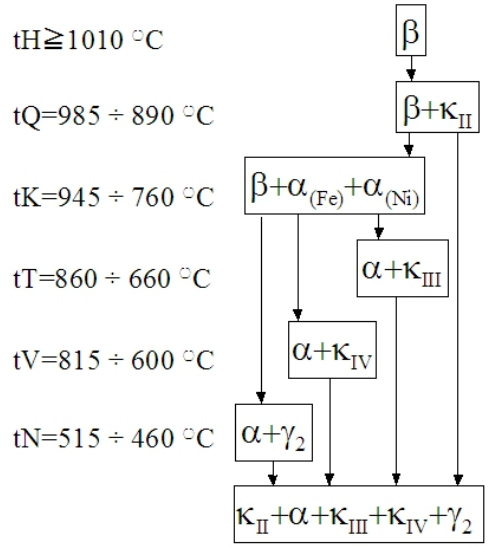

Fig. 7. Phase transformation during cooling $\mathrm{Cu}-\mathrm{Al}-\mathrm{Fe}-\mathrm{Ni}$ bronzes with limited additions of $\mathrm{Cr}, \mathrm{Mo}, \mathrm{W}$ and/or $\mathrm{Si}$

\section{Conclusions}

The following conclusions result from the presented study:

- elaborated model of crystallization and phase transformation in the solid state hypo-eutectoid $\mathrm{Cu}-\mathrm{Al}-\mathrm{Fe}-\mathrm{Ni}$ bronze, crystallize without a MM X intermetallic phases (where $\mathrm{X}=\{\mathrm{Mo}, \mathrm{W}, \mathrm{Cr}, \mathrm{MoWCr}\}$ ) and $\kappa_{\mathrm{I}}$ defines:

$\circ$ the type of crystallizing phases,

0 the order of crystallizing phases,

○ the place of nucleation,

- $\quad$ studies it possible to determine the actual temperature ranges of phase transformations in $\mathrm{Cu}-\mathrm{Al}-\mathrm{Fe}-\mathrm{Ni}$ bronze with low quantity of additions of $\mathrm{Cr}, \mathrm{Mo}, \mathrm{W}$ and/or $\mathrm{Si}$,

- knowledge of the actual temperature ranges of phase transformations in the studied bronzes, allows you to control the microstructure of the bronze after heat treatment. 


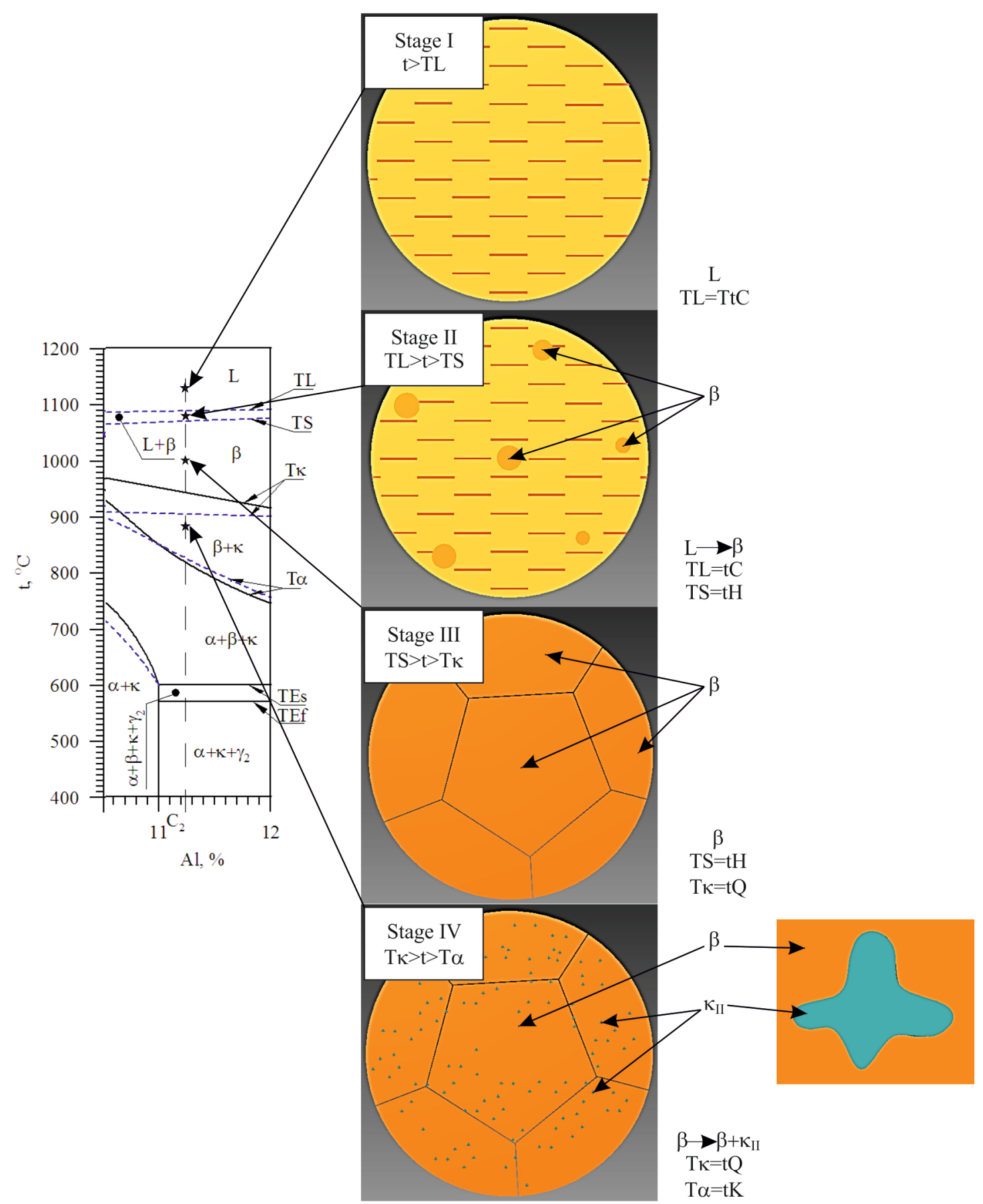

Fig. 6. The Model of crystallization and phase transformation in the solid state hypo-eutectoid $\mathrm{Cu}-\mathrm{Al}-\mathrm{Fe}-\mathrm{Ni}$ bronzes without intermetallic phases type of a MM_X (where $\mathrm{X}=\{\mathrm{Mo}, \mathrm{W}, \mathrm{Cr}, \mathrm{MoWCr}\})$ and $\kappa_{\mathrm{I}}$ 


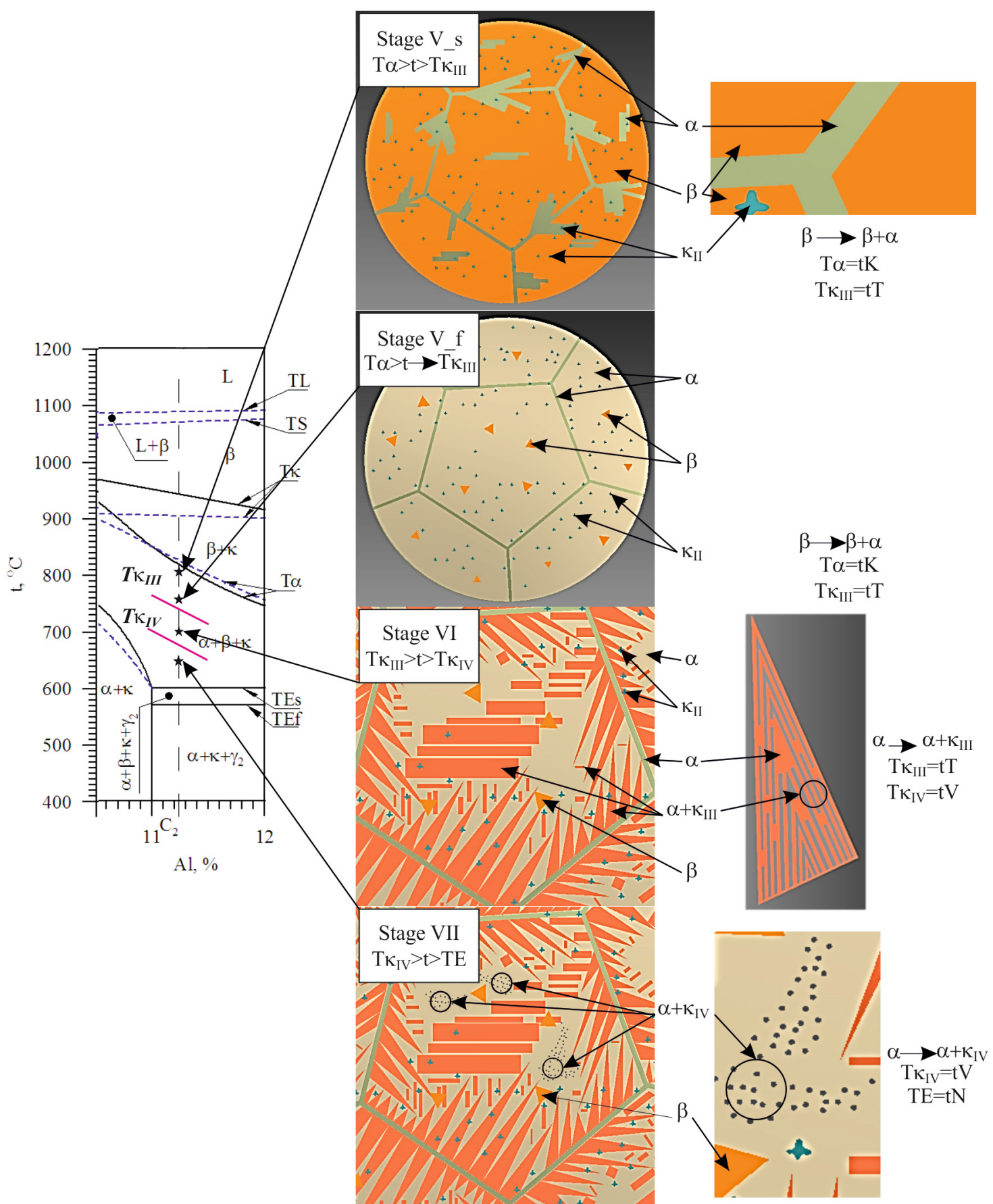

Fig. 6. (cont.) The model of crystallization and phase transformation in the solid state hypo-eutectoid $\mathrm{Cu}-\mathrm{Al}-\mathrm{Fe}-\mathrm{Ni}$ bronzes without intermetallic phases type of a MM X (where $\mathrm{X}=\{\mathrm{Mo}, \mathrm{W}, \mathrm{Cr}, \mathrm{MoWCr}\}$ ) and $\kappa_{\mathrm{I}}$ 

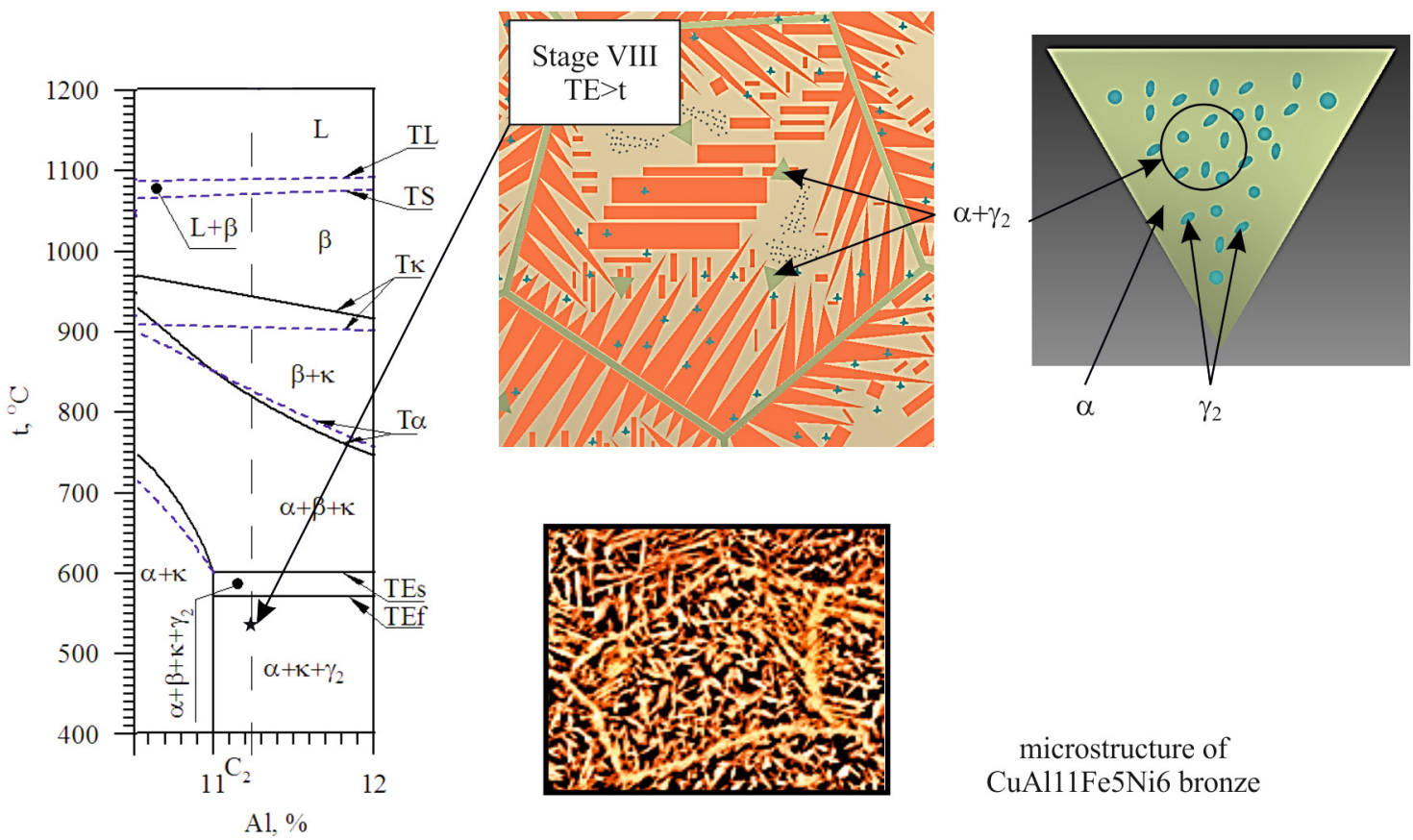

microstructure of
CuAl11Fe5Ni6 bronze

Fig. 6. (cont.) The model of crystallization and phase transformation in the solid state hypo-eutectoid Cu-Al-Fe-Ni bronzes without intermetallic phases type of a MM_X (where $\mathrm{X}=\{\mathrm{Mo}, \mathrm{W}, \mathrm{Cr}, \mathrm{MoWCr}\})$ and $\kappa_{\mathrm{I}}$

\section{Acknowledgements}

The work was conducted in the frames of the research project N N508 399137- financed with the sources for the science in the years 2009-2012 by the Ministry of Science and Higher Education.

\section{References}

[1] Brezina, P. (1973). Gefügeumwandlungen und mechanische Eigenschaften der Mehrstoff-Aluminiumbronzen vom Typ CuAl10 Fe5 Ni5. Giesserei-Forschung. 25(3), 1-10.

[2] Cook, M., Fentimen, W.P. \& Davis, E. (1951-52). Observations on the structure and properties of wrought cooper-aluminiumnickel-iron alloys, J. Inst. Metals. 80, 419/29.

[3] Brezina, P. (1973). Gefögeumwandlungen und mechanische Eigenschaften der Mehrstoff-Aluminiumbronzen vom Typ CuAl 10 Fe5 Ni5. Giesserei-Forschung, 25(3), 1-10.

[4] Hasan, F., Jahanafrooz, A., Lorimer, G.W. \& Ridley, N. (1982). The Morphology, Crystallography, and Chemistry of Phases in As-Cast Nickel-Aluminum Bronze. Met. Trans A. 13a, 13371345.

[5] Jahanafrooz, A., Hasan, F., Lorimer, G.W. \& Ridley, N. (1983). Microstructural Development in Complex Nickel-Aluminum Bronze. Met. Trans A. 14a, 1951-1956.

[6] Fuller, M.D. (2006). Friction Stir Processing and Fusion Welding in Nickel Aluminum Propeller Bronze. Thesis, Thesis Advisor: Terry R. McNelley, Naval Postgraduate School, Monterey, California, USA.
[7] Weill-Couly, P. \& Arnaud, D. (1973). Influence De La Composition Et De La Structure Des Cupro-Aluminiums Sur Leur Comportment En Service. Fonderie. 322, 123-135.

[8] Gumienny, G. (2011). TDA method application to austenite transformation in nodular cast iron with carbides assessment. Archives of Foundry Engineering. 11(3), 159-166.

[9] Gumienny, G. (2010). Bainitic-martensitic nodular cast iron with carbides. Archives of Foundry Engineering. 10(2), 63-68.

[10] Pietrowski, S. \& Szymczak, T. (2009). Silumins alloy crystallization. Archives of Foundry Engineering. 9(3), 143-158.

[11] Pietrowski S. \& Szymczak, T. (2010). Crystallization, microstructure and mechanical properties of silumins with microadditions of Cr, Mo, W and V. Archives of Foundry Engineering. 10(1), 123-136.

[12] Pisarek, B. (2007). The crystallization of the bronze with additions of Si, Cr, Mo and/or W. Archives of Materials Science and Engineering. 28(8), 461-466.

[13] Pisarek, B. (2010). Influence of the technology of melting and inoculation preliminary alloy $\mathrm{AlBe} 5$ on change of concentration of $\mathrm{Al}$ and microstructure of the bronze $\mathrm{CuAl10Ni5Fe} 4$. Archives of Foundry Engineering. 10(2), 127-134.

[14] Pisarek, B. (2011). Effect of additions Cr, Mo, W and/or Si on the technological properties on the technological properties of aluminium-iron-nickel bronze. Archives of Foundry Engineering. 11(3), 199-208.

[15] Pisarek, B. (2012). Effect of annealing time for quenching $\mathrm{CuAl7Fe} 5 \mathrm{Ni} 5 \mathrm{~W} 2 \mathrm{Si} 2$ bronze on the microstructure and mechanical properties. Archives of Foundry Engineering. 12(2), 187204.

[16] Pietrowski, S. \& Pisarek, B. (2007). Computer-aided technology of melting high-quality metal alloys. Archives of Metallurgy and Materials. 52(3), 481-486. 